OLIVEIRA, Heron José Castro. Estado de direito e estado democrático de direito (estado social): o que há de novo?. Revista Eletrônica Direito e Política, Programa de Pós-Graduação Stricto Sensu em Ciência Jurídica da UNIVALI, Itajaí, v.11, n.3, 30 quadrimestre de 2016. Disponível em: www.univali.br/direitoepolitica - ISSN 1980-7791.

\title{
ESTADO DE DIREITO E ESTADO DEMOCRÁTICO DE DIREITO (ESTADO SOCIAL): O QUE HÁ DE NOVO?
}

\author{
RULE OF LAW AND "DEMOCRATIC STATE" (WELFARE STATE): WHAT'S NEW?
}

\author{
Heron José Castro Oliveira ${ }^{1}$
}

SUMÁRIO: Introdução; 1 . O conceito de estado de direito; 2. Isonomia; 3. A liberdade negativa; 4. O estado democrático de direito (estado social); 5. Diferenças entre as duas formas de estado; Considerações finais; Referências das fontes citadas.

\section{RESUMO}

A partir da pesquisa dos clássicos e através do método dedutivo, será abordado o conceito de Estado de Direito (rule of law), Estado Social (welfare state) e Estado Democrático de Direito, porém, visando estabelecer se os dois últimos realmente são diferentes, como sustenta a maioria da doutrina. O tema é importante devido ao risco de se cair no senso comum acadêmico, por mais que a transição entre estes estados já tenha sido trabalhada, é raro a pesquisa questionando os seus significados e elementos. Autores como Manoel Gonçalves Ferreira Filho abordam a transição entres os três e constatam a ausência de valores que diferenciem o welfare state e o Estado Democrático de Direito. Nós chegamos a conclusão de que se o Estado Social "socializou" a ideia de isonomia e liberdade negativa, bases do rule of law, tal "socialização" não apresentou mudanças desde então.

Palavras-Chaves: Estado de Direito. Estado Social. Estado Democrático de Direito.

ABSTRACT: With a search of the classic and a deductive method, will be addressed the concept of rule of law, welfare state and Democratic State, however, to establish if the last two are really different, how to sustain the majority of doctrine. The issue is important because of the risk of falling in the academic common sense, much as the transition between these states has already been worked out, research is often questioning their meanings and elements. Authors such as Manoel Gonçalves Ferreira Filho discuss the transition between these three states founded and observe the absence of values that differentiate the welfare state and the Democratic State.

\footnotetext{
1 Bacharelando em Direito no $10^{\circ}$ semestre pelo Centro Universitário de Brasília (UniCEUB). Brasília/DF. Estudante universitário. Email: heroncastro93@gmail.com
} 
OLIVEIRA, Heron José Castro. Estado de direito e estado democrático de direito (estado social): o que há de novo?. Revista Eletrônica Direito e Política, Programa de Pós-Graduação Stricto Sensu em Ciência Jurídica da UNIVALI, Itajaí, v.11, n.3, 30 quadrimestre de 2016. Disponível em: www.univali.br/direitoepolitica - ISSN 1980-7791.

We conclude that the welfare state "socialized" the idea of equality and negative freedom, the rule of law bases, such "socialization" showed no changes since.

Keywords: Rule of law. Welfare satate. Democratic State.

\section{INTRODUÇÃO}

O presente trabalho busca abordar aspectos sobre o Estado de Direito, analisando suas duas ideias centrais, a liberdade e a isonomia. Também será feita uma comparação entre esse instituto clássico e a ideia contemporânea de Estado Democrático de Direito, e como a liberdade e a isonomia são tratados neste novo estado.

Examinaremos o período de evolução entre o Estado de Direito setecentista, passando pelo Estado Social, até sua chegada ao Estado Democrático de Direito, não será abordado aquilo que alguns doutrinadores afirmam ser uma nova fase do direito constitucional, o neoconstitucionalismo. Este para alguns autores chega a significar uma ameaça ao Estado de Direito (se é que ele ainda existe) ${ }^{2}$.

Neste trabalho primeiro conceituaremos Estado de Direito, para depois analisarmos o que é liberdade negativa e isonomia e como ambas são tratadas atualmente. Mais ao final será conceituado o Estado Democrático de Direito, fazendo um paralelo entre este e o Estado Social, que também será abordado, para por último compararmos o conceito de Estado de Direito com Estado Democrático de Direito.

Este artigo foi desenvolvido com base em conceitos extraídos de pensadores clássicos (Monstesquieu, Locke e Bastiat ${ }^{3}$ ), uma vez que tais autores marcaram o início do movimento constitucionalista, do qual emergiu a instituição chamada Estado

\footnotetext{
${ }^{2}$ O professor Jorge Octávio Lavocat Galvão, expõe as transformações que a corrente chamada neoconstitucionalismo traz ao Estado de Direito, no livro O neoconstitucionalismo e o fim do Estado de Direito.

${ }^{3}$ Frederic Bastiat foi um político, jornalista, filósofo e panfletário francês, que viveu na primeira metade do século XVIII. Por mais que não seja tão conhecido quanto seu conterrâneo Montesquieu, a obra de Bastiat mostra de forma clara a ideia de qual seria a real função da lei, o que é necessário para entender o Estado de Direito.
} 
OLIVEIRA, Heron José Castro. Estado de direito e estado democrático de direito (estado social): o que há de novo?. Revista Eletrônica Direito e Política, Programa de Pós-Graduação Stricto Sensu em Ciência Jurídica da UNIVALI, Itajaí, v.11, n.3, 30 quadrimestre de 2016. Disponível em: www.univali.br/direitoepolitica - ISSN 1980-7791.

de Direito, além de ser leitura obrigatória para entendermos o conceito básico dessa instituição.

Manoel Gonçalves Ferreira Filho, que em sua obra é muito influenciado por Montesquieu, é a fonte da maior parte da bibliografia do presente artigo, mas não deixaremos, é obvio, de analisar os contrapontos ao autor, os professores José Afonso da Silva, Paulo Bonavides e Canotilho, que demonstram uma visão diferente do que seria o Estado Democrático de Direito.

A importância do tema também se deve ao fato do rule of law, querendo ou não, ter influenciado de forma significativa a sociedade ocidental, principalmente após as revoluções liberais do século XVII. Como será mostrado, em nossa atual constituição, ainda notamos heranças dessa ideia. E não há como entender uma instituição sem antes entender a sua formação e seu conceito.

A escolha por analisar o Estado de Direito à luz da isonomia e da liberdade, que não são os seus únicos princípios, deve-se ao fato destes serem os primeiros valores que vem à mente ao se lembrar dessa forma de estado, se mantendo até hoje em nossa Carta Magna, em certa medida.

Destarte, a pesquisa foi desenvolvida com base em autores clássicos, tanto os nacionais como os estrangeiros, e no método dedutivo.

Ao estudarmos a evolução do conceito de Estado de Direito, até Estado Democrático de Direito, sem esquecer de analisar o Estado Social, pretendemos demonstrar se o contraponto ao rule of law, o Estado Social, ainda não estaria vigente no atual momento histórico, sobre uma denominação diferente (Estado Democrático de Direito), o que é negado na maioria dos manuais de direito constitucional.

Ou seja, não se está diante de uma estratégia de alguns constitucionalistas, dentro de um senso comum acadêmico, para que seja adotado um estado intervencionista, com um nome mais atraente? 
OLIVEIRA, Heron José Castro. Estado de direito e estado democrático de direito (estado social): o que há de novo?. Revista Eletrônica Direito e Política, Programa de Pós-Graduação Stricto Sensu em Ciência Jurídica da UNIVALI, Itajaí, v.11, n.3, 30 quadrimestre de 2016. Disponível em: www.univali.br/direitoepolitica - ISSN 1980-7791.

\section{O CONCEITO DE ESTADO DE DIREITO}

Para conceituar Estado de Direito, deve ser levada em consideração a ideia de que a lei regula as relações sociais. Segundo Ronald Dworkin ${ }^{4}$, há duas ideias de Estado de Direito, uma centrada no texto legal e outra nos direitos ${ }^{5}$.

A ideia de Estado de Direito centrada no texto legal é a seguinte:

O governo, assim como os cidadãos comuns, devem agir segundo essas regras públicas até que elas sejam mudadas, em conformidade com regras adicionais sobre como elas devem ser mudadas, que também são especificadas no conjunto de normas ${ }^{6}$.

Com relação à ideia centrada nos direitos, Dworkin expõe:

O Estado de Direito dessa concepção é o ideal de governo por meio de uma concepção pública precisa dos direitos individuais. Não distingue, como faz a concepção centrada no texto legal, entre o Estado de Direito e a justiça substantiva; pelo contrário, exige, como parte do ideal do Direito, que o texto legal retrate os direitos morais e o aplique ${ }^{7}$.

O conceito fundado nos direitos parece ser a mais adequada ao pensamento clássico, tendo em vista as visões de pensadores da época, muito baseadas na ideia de direitos naturais.

Segundo a lição de Montesquieu: "Antes da existência das leis elaboradas havia relações de justiça possíveis" ${ }^{8}$. Para outro conterrâneo de Montesquieu, Frederic

\footnotetext{
${ }^{4}$ Optamos por expor o pensamento de Dworkin, devido ao fato deste jurista estadunidense ter realizado a síntese mais adequada entre as duas visões de Estado de Direito, mesmo o tema não sendo o principal objeto de estudo de suas obras.

${ }^{5}$ DWORKIN, Ronald. Uma questão de princípio. Tradução: Luís Carlos Borges. São Paulo: Martins Fontes, 2001, p. 6/7.

6 DWORKIN, Ronald. Uma questão de princípio. Tradução: Luís Carlos Borges. São Paulo: Martins Fontes, 2001, p. 7.

7 DWORKIN, Ronald. Uma questão de princípio. Tradução: Luís Carlos Borges. São Paulo: Martins Fontes, 2001, p. 7.

8 MONTESQUIEU, Charles de Secondat Baron. O espírito das leis. Tradução: Cristina Marachco. 3. ed. São Paulo: Martins Fontes, 2005, p. 12.
} 
OLIVEIRA, Heron José Castro. Estado de direito e estado democrático de direito (estado social): o que há de novo?. Revista Eletrônica Direito e Política, Programa de Pós-Graduação Stricto Sensu em Ciência Jurídica da UNIVALI, Itajaí, v.11, n.3, 30 quadrimestre de 2016. Disponível em: www.univali.br/direitoepolitica - ISSN 1980-7791.

Bastiat, a lei não existiria se antes de tudo não houvesse três elementos básicos: vida, liberdade e propriedade 9 . A ideia de justiça advém do fato de haver leis naturais, que foram estabelecidas antes do ser humano se organizar em sociedade ${ }^{10}$.

Nas palavras de Manoel Gonçalves Ferreira Filho, "está bem claro, perquiridas as origens do Estado de direito, que este visava a estabelecer o império da justiça, não da lei, vista esta como vontade do legislador"11.

O professor também ensina: "Estas leis positivas - insista-se - não eram válidas senão na medida em que se ajustassem ao direito superior"12.

Fica claro, pela lição da literatura, que a ideia de Estado de Direito como centrado apenas na letra da lei não tem valor se esta não abarcar a ideia de justiça, que é anterior ao texto normativo.

O Estado de Direito não pode se resumir ao simples fato de sermos governados por lei, como se a justiça não fosse algo importante, esse é outro motivo pelo qual, dos dois conceitos expostos por Dworkin, o modelo centrado na ideia de direitos é o modelo clássico dessa concepção.

Como bem ensina o jurista estadunidense: "embora o modelo centrado nos direitos admita que o texto jurídico é, dessa maneira, uma fonte dos direitos morais no tribunal, ele nega que o texto jurídico seja a fonte exclusiva de tais direitos" ${ }^{13}$.

\footnotetext{
${ }^{9}$ BASTIAT, Frederic. A Lei. Tradução: Ronaldo da Silva Legey. 3. ed. São Paulo: Instituto Ludwig von Mises Brasil, 2010, p. 11.

${ }^{10}$ MONTESQUIEU, Charles de Secondat Baron. O espírito das leis. Tradução: Cristina Marachco. 3. ed. São Paulo: Martins Fontes, 2005, p. 13/14.

${ }^{11}$ FERREIRA FILHO, Manoel Gonçalves. As origens do estado de direito, 1987. Disponível em: <http://bibliotecadigital.fgv.br/ojs/index.php/rda/article/download/45514/43918> Acesso em: 5 jul. 2015.

12 FERREIRA FILHO, Manoel Gonçalves. As origens do estado de direito, p. 4. Disponível em: <http://bibliotecadigital.fgv.br/ojs/index.php/rda/article/download/45514/43918> Acesso em: 5 jul. 2015.

13 DWORKIN, Ronald. Uma questão de princípio. Tradução: Luís Carlos Borges. São Paulo: Martins Fontes, 2001, p. 15.
} 
OLIVEIRA, Heron José Castro. Estado de direito e estado democrático de direito (estado social): o que há de novo?. Revista Eletrônica Direito e Política, Programa de Pós-Graduação Stricto Sensu em Ciência Jurídica da UNIVALI, Itajaí, v.11, n.3, 30 quadrimestre de 2016. Disponível em: www.univali.br/direitoepolitica - ISSN 1980-7791.

Ou seja, o Estado de Direito é o ideal inglês rule of law ${ }^{14}$. Lembrando que rule of law significa "a sujeição de todos, inclusive e especialmente das autoridades, ao império do Direito. Equivale, pois, ao Estado de Direito como limitação do poder, num sistema de direito não escrito"15. Eis a melhor conceituação de Estado de Direito.

Cabe observar que essa concepção, centrada nos direitos, não se espelha nas ideias de Hobbes, filósofo importante em qualquer estudo sobre teoria do estado, para quem a lei é um comando obrigatório ${ }^{16}$. Outra visão do pensador inglês, que em muito se distancia do ideal baseado no direito, é o fato de o soberano não precisar obedecer às leis civis ${ }^{17}$.

Lembremos que tais direitos, como ensina Dworkin, são escritos em um texto. Logo, cabe mencionar aqui as Declarações de Direitos do final do século XVII, que praticamente fundaram o Estado de Direito. Recordamos também que esses documentos "especificam direitos individuais, próprios a todos os seres humanos, sem exceção, com abstração de peculiaridades como a vinculação ao povo de determinado estado"18.

Ou seja, duas coisas podem ser percebidas a partir da ligação entre Estado de Direito e declarações: a) o Estado de Direito tem como suas duas bases chaves, mas não as únicas, a isonomia e a liberdade; e b) o Estado de Direito é um instituto ligado ao liberalismo.

Sem um Estado que respeite as leis, em que a lei seja aplicada de forma igual perante todos, e esta lei tenha em seu conteúdo a proteção do indivíduo perante a

\footnotetext{
${ }^{14}$ FERREIRA FILHO, Manoel Gonçalves. As origens do estado de direito, 1987, p. 5. Disponível em: <http://bibliotecadigital.fgv.br/ojs/index.php/rda/article/download/45514/43918> Acesso em: 5 jul. 2015.

${ }^{15}$ FERREIRA FILHO, Manoel Gonçalves. Direitos humanos fundamentais. 14. ed. São Paulo: Saraiva, 2012, p. 30.

${ }^{16}$ HOBBES, Thomas. Leviatã. Tradução: João Paulo Monteiro, Maria Beatriz Nizza da Silva, Cláudia Berliner. São Paulo: Martins Fontes, 2003, p. 226.

${ }^{17}$ HOBBES, Thomas. Leviatã. Tradução: João Paulo Monteiro, Maria Beatriz Nizza da Silva, Cláudia Berliner. São Paulo: Martins Fontes, 2003, p. 227.
}

18 FERREIRA FILHO, Manoel Gonçalves. Estado de Direito e Constituição. 4. ed. São Paulo: Saraiva, 2007, p. 15. 
OLIVEIRA, Heron José Castro. Estado de direito e estado democrático de direito (estado social): o que há de novo?. Revista Eletrônica Direito e Política, Programa de Pós-Graduação Stricto Sensu em Ciência Jurídica da UNIVALI, Itajaí, v.11, n.3, 30 quadrimestre de 2016. Disponível em: www.univali.br/direitoepolitica - ISSN 1980-7791.

opressão estatal, não haveria segurança jurídica e nem a concretização de uma vida digna aos indivíduos.

Lamenta-se o fato da ideia de lei, e assim também a de rule of law, ser banalizada nos dias atuais, e a sociedade ser alvo de uma verdadeira inflação legislativa. No Brasil já foram promulgadas mais de 7000 leis após 1964, sendo que no império, período que durou 67 anos, foram promulgadas 3.400 leis $^{19}$.

\section{ISONOMIA}

O Estado de Direito tem entre seus pilares a isonomia, ou seja, a igualdade formal ${ }^{20}$. Segundo Hayek:

O termo isonomia foi trazido para a Inglaterra da Itália, no final do século XVI, com o significado de "leis aplicáveis igualmente a todos"; logo depois, era usado livremente pelo tradutor de Tito Lívio na forma anglicizada isonomy para definir um estado de leis gerais, aplicáveis igualmente a todos, e de responsabilidade dos magistrados ${ }^{21}$.

O princípio da isonomia está disposto na primeira parte do artigo $1^{0}$ da Declaração Universal dos Direitos do Homem de 1789: "Os homens nascem e são livres e iguais em direitos".

No início do artigo $6^{\circ}$ da mesma declaração, tal ideal também aparece: "Ela deve ser a mesma para todos, seja para proteger, seja para punir". A atual Constituição Federal estatui comando semelhante no caput de seu artigo 50: "Todos são iguais perante a lei, sem distinção de qualquer natureza, garantindo-se aos brasileiros e aos estrangeiros residentes no País a inviolabilidade do direito à vida, à liberdade, à igualdade, à segurança e à propriedade, nos termos seguintes".

19 FERREIRA FILHO, Manoel Gonçalves. Do processo legislativo. 70. Ed. São Paulo: Saraiva, 2012 , p. 34.

${ }^{20}$ FERREIRA FILHO, Manoel Gonçalves. Direitos humanos fundamentais. 14. ed. São Paulo: Saraiva, 2012, p. 44/45.

${ }^{21}$ HAYEK, Friedrich. Os fundamentos da liberdade. Tradução: Anna Maria Capovilla e José Ítalo Stelle. Brasília: UNB/Visão, 1983, p. 185/186. 
OLIVEIRA, Heron José Castro. Estado de direito e estado democrático de direito (estado social): o que há de novo?. Revista Eletrônica Direito e Política, Programa de Pós-Graduação Stricto Sensu em Ciência Jurídica da UNIVALI, Itajaí, v.11, n.3, 30 quadrimestre de 2016. Disponível em: www.univali.br/direitoepolitica - ISSN 1980-7791.

Aqui vale lembrar os ensinamentos de John Locke, para quem após a comunidade conseguir excluir o juízo de cada indivíduo, ela passa a ser árbitro através de normas fixas estabelecidas, neutras e iguais a todas as partes ${ }^{22}$.

Não se trata, pois, do conceito de igualdade que predomina nos dias atuais, a igualdade material, ou, como denomina Norberto Bobbio, "igualdade de fato". A diferença consiste devido a "igualdade de fato", base do Estado Social, refletir a ideia de "igualdade com relação aos bens materiais" 23 .

Ou seja, a igualdade do Estado de Direito é uma igualdade formal, ante a lei, como isto não interferia na vida concreta das pessoas posteriormente surge, como veremos, o Estado Social/Estado Democrático de Direito ${ }^{24}$.

$\mathrm{Na}$ atual Carta Magna, como já exposto, a ideia de igualdade perante a lei encontrase positivada (art. 50, caput). Sendo assim, só poderá acontecer algum tratamento jurídico diferencial nos termos da própria constituição ${ }^{25}$.

Além de abarcar a ideia de igualdade perante a lei, o princípio da igualdade no Estado de Direito também abraça o ideal de proibição de discriminação e uniformidade de tratamento ${ }^{26}$. Porém, é a ideia de igualdade diante das normas que ficou para posteridade e que é mais abordada pela doutrina:

O primeiro significado, pois, do princípio constitucional de igualdade é o da uniformização do estatuto jurídico para todos os homens. É a igualdade perante o direito em geral, perante o direito como sistema. E disto resulta a proibição de que, em razão de nascimento, raça, credo religioso ou de convicções

\footnotetext{
22 LOCKE, John. Dois tratados sobre o governo. Tradução: Júlio Fischer. São Paulo: Martins Fontes, 2001, p. 458.

23 BOBBIO, Norberto. Igualdade e Liberdade. Tradução: Carlos Nelson Coutinho. 5. ed. Rio de Janeiro: Ediouro, 1997, p. 32.
}

24 DA SILVA, José Afonso. Curso de Direito Constitucional Positivo. 37. ed. São Paulo: Malheiros, 2014, p. 120.

25 FerreirA FILHO, Manoel Gonçalves. Curso de Direito Constitucional. 38. ed. São Pulo: Saraiva, 2012, p. 312.

${ }^{26}$ FERREIRA FILHO, Manoel Gonçalves. Estado de Direito e Constituição. 4. ed. São Paulo: Saraiva, 2007, p. 27. 
OLIVEIRA, Heron José Castro. Estado de direito e estado democrático de direito (estado social): o que há de novo?. Revista Eletrônica Direito e Política, Programa de Pós-Graduação Stricto Sensu em Ciência Jurídica da UNIVALI, Itajaí, v.11, n.3, 30 quadrimestre de 2016. Disponível em: www.univali.br/direitoepolitica - ISSN 1980-7791.

políticas, se estabeleça distinções quanto ao estado jurídico ou se criem privilégios, de qualquer espécie ${ }^{27}$.

Porém, a isonomia, o que nos levava a sermos iguais perante a lei, também se encontra praticamente desvalorizada no presente momento. Como já exposto, a ideia de lei perdeu seu valor, devido a inflação legislativa, o que não é diferente para o princípio da isonomia. A partir do momento histórico em que o sistema capitalista gerou desigualdade econômica ${ }^{28}$, a comunidade intelectual, entendeu que não mais bastava a igualdade de tratamento legal, mas também a igualdade material (pilar do Estado Social).

\section{A LIBERDADE NEGATIVA}

Para Monstesquieu: "A liberdade é o direito de fazer tudo que as leis permitem"29. Já para o pai do liberalismo, Locke, a liberdade "consiste em viver segundo uma regra permanente, comum a todos nessa sociedade e elaborado pelo legislativo nela erigido" ${ }^{30}$. Ou seja, a liberdade, para os Montesquieu e Locke, está ligada a ideia de lei, a lei estipulando os limites da ação do indivíduo.

Como já foi exposto o Estado de Direito é a ideia de rule of law, que surgiu para limitar o poder do Estado, pois este é adversário da liberdade ${ }^{31}$. Por essa concepção de liberdade obrigar um não fazer do poder estatal, é dado o nome de liberdade negativa à liberdade dessa instituição clássica. Mas o que é liberdade negativa?

\footnotetext{
27 FerReirA FILHO, Manoel Gonçalves. Estado de Direito e Constituição. 4. ed. São Paulo: Saraiva, 2007, p. 28.

${ }^{28}$ Mesmo já sendo um tema muito debatido, a questão da desigualdade econômica gerada pelo capitalismo, há material demonstrando um ponto de vista ainda pouco presente no Brasil. Este material (artigos, vídeos e ebooks) podem ser obtidos gratuitamente no sitio eletrônico mises.org.br.
}

${ }^{29}$ MONTESQUIEU, Charles de Secondat Baron. O espírito das leis. Tradução: Cristina Marachco. 3. ed. São Paulo: Martins Fontes, 2005, p. 166.

${ }^{30}$ LOCKE, John. Dois tratados sobre o governo. Tradução: Júlio Fischer. São Paulo: Martins Fontes, 2001, p. 403.

${ }^{31}$ FerReIRA FILho, Manoel Gonçalves. Estado de Direito e Constituição. 4. ed. São Paulo: Saraiva, 2007, p. 03. 
OLIVEIRA, Heron José Castro. Estado de direito e estado democrático de direito (estado social): o que há de novo?. Revista Eletrônica Direito e Política, Programa de Pós-Graduação Stricto Sensu em Ciência Jurídica da UNIVALI, Itajaí, v.11, n.3, 30 quadrimestre de 2016. Disponível em: www.univali.br/direitoepolitica - ISSN 1980-7791.

Por liberdade negativa adotamos o conceito de Bobbio, para quem aquela é "a situação na qual um sujeito tem a possibilidade de agir sem ser impedido, ou de não agir sem ser obrigado por outros sujeitos" ${ }^{\prime 2}$.

A liberdade negativa está na base do Estado de Direito, devido ao fato de o constitucionalismo ter como função maior a proteção do indivíduo contra o Estado. A ideia de lei em si visava, em seu início, limitar o poder estatal para que este proteja a liberdade, a vida e a propriedade, sendo que nos locais em que o poder estatal se mantém dentro desses limites, haverá o governo ideal ${ }^{33}$.

Dimitri Dimoulis e Leonardo Martins dão como exemplo o fato de o Estado não poder praticar a censura contra jornalistas, nesse caso estes terão o direito fundamental à resistência ${ }^{34}$.

Para se entender o motivo da preocupação em defender os indivíduos do estado, é preciso levar em consideração a análise histórica, que concluirá "que os Poderes, especialmente o Legislativo e o Executivo, podem tornar-se violadores dos direitos fundamentais" ${ }^{35}$. Aqui, por direitos fundamentais se consideram os direitos de primeira geração, ou seja, as liberdades negativas.

Atualmente essa ideia de liberdade, como liberdade negativa, está sendo mitigada devido à maior interferência do estado no plano econômico. Ao lado da ideia clássica do constitucionalismo como limitação da atuação do estado na vida do particular, surgiu uma exigência do Estado: garantir que essas liberdades sejam exercidas, ou

\footnotetext{
32 BOBBIO, Norberto. Igualdade e Liberdade. Tradução: Carlos Nelson Coutinho. 5. ed. Rio de Janeiro: Ediouro, 1997, p. 48.

33 BASTIAT, Frederic. A Lei. Tradução: Ronaldo da Silva Legey. 3. ed. São Paulo: Instituto Ludwig von Mises Brasil, 2010, p. 12.

${ }^{34}$ DIMOULIS, Dimitris; MARTINS, Leonardo. Teoria Geral dos Direitos Fundamentais. 4. ed. São Paulo: Atlas, 2012, p. 49/50.
}

35 FERREIRA FILHO, Manoel Gonçalves. Direitos humanos fundamentais. 14. ed. São Paulo: Saraiva, 2012, p. 91. 
OLIVEIRA, Heron José Castro. Estado de direito e estado democrático de direito (estado social): o que há de novo?. Revista Eletrônica Direito e Política, Programa de Pós-Graduação Stricto Sensu em Ciência Jurídica da UNIVALI, Itajaí, v.11, n.3, 30 quadrimestre de 2016. Disponível em: www.univali.br/direitoepolitica - ISSN 1980-7791.

seja, o Estado passa a atuar e não a se omitir. Essa mudança tem como marco a Constituição alemã de $1919^{36}$.

\section{O ESTADO DEMOCRÁTICO DE DIREITO (ESTADO SOCIAL)}

Segundo a maioria da doutrina, antes da transição do Estado de Direito para o Estado Democrático de Direito, houve o surgimento do Estado Social. Este último aparece como uma forma de combater "o individualismo e o abstencionismo ou neutralismo do Estado liberal" 37 que teriam provocado "imensas injustiças [...] desvelando a insuficiência das liberdades burguesas" ${ }^{38}$. Mas há diferença entre Estado Social e Estado Democrático de Direito?

A expressão Estado Democrático de Direito foi criada pelo espanhol Elis Díaz para expressar aquele estado que visa à transição para o socialismo ${ }^{39}$. Logicamente o constituinte de 1988, ao definir que o Brasil constitui um Estado Democrático de Direito (art. 10, caput, CF/88), não tinha isso em mente, porém, segundo constitucionalistas como Jorge Miranda, Estado Democrático de Direito e Estado Social não passam de sinônimos ${ }^{40}$.

Se a atual Lei Maior, não visava a transição para o socialismo, não há como negar sua preferência por direitos sociais em detrimento da liberdade negativa e da isonomia. Isto é, a busca da atual constituição é a realização da chamada justiça

\footnotetext{
${ }^{36}$ FerReirA FILHO, Manoel Gonçalves. Curso de Direito Constitucional. 38. ed. São Pulo: Saraiva, 2012, p. 320.

37 Por "abstencionismo ou neutralismo", podem-se entender os princípios expostos anteriormente no presente artigo, ou seja, a liberdade e a isonomia.
}

38 DA SILVA, José Afonso. Curso de Direito Constitucional Positivo. 37. ed. São Paulo: Malheiros, 2014, p. 117.

${ }^{39}$ FERREIRA FILHO, Manoel Gonçalves. Estado de Direito e Constituição. 4. ed. São Paulo: Saraiva, 2007, p. 65.

40 FerreirA FILHO, Manoel Gonçalves. Curso de Direito Constitucional. 38. ed. São Pulo: Saraiva, 2012, p. 344. 
OLIVEIRA, Heron José Castro. Estado de direito e estado democrático de direito (estado social): o que há de novo?. Revista Eletrônica Direito e Política, Programa de Pós-Graduação Stricto Sensu em Ciência Jurídica da UNIVALI, Itajaí, v.11, n.3, 30 quadrimestre de 2016. Disponível em: www.univali.br/direitoepolitica - ISSN 1980-7791.

social ${ }^{41}$, o que nos leva a poder afirmar que o Estado Democrático de Direito abraça a ideia de Estado Social (welfare state), visto que seu conceito em muito traz a ideia de justiça social. Vejamos:

É um tipo de Estado que tende a realizar a síntese do processo contraditório do mundo contemporâneo, superando o Estado capitalista para configurar um Estado promotor de justiça social que o personalismo e o monismo político das democracias populares sob o influxo do socialismo real não foram capazes de construir ${ }^{42}$.

O fato da Constituição de 1988 definir que o Brasil é um Estado Democrático de Direito, corrobora com a tese aqui defendida, de que o Estado Social surgido no início do século XX, não mudou com o "surgimento" do Estado Democrático de Direito no final do século $X X$, apenas ganhou um nome mais atrativo. Na afirmação de Paulo Bonavides ${ }^{43}$ a "Constituição de 1988 é basicamente em muitas de suas dimensões essenciais uma Constituição do Estado social"44.

Outros constitucionalistas tentam esconder esta ideia, afirmando que o Estado Democrático de Direito - ou como chamam os portugueses "Estado de direito democrático" - significa a soma do ideal de rule of law com a ideia de democracia, e de que todo o poder deve ser exercido de forma democrática ${ }^{45}$.

Porém, Canotilho também expõe a dúvida a respeito da visão de liberdade no Estado de Direito e no Estado Democrático:

41 DA SILVA, José Afonso. Curso de Direito Constitucional Positivo. 37. ed. São Paulo: Malheiros, 2014, p. 122.

42 DA SILVA, José Afonso. Curso de Direito Constitucional Positivo. 37. ed. São Paulo: Malheiros, 2014, p. 122.

43 Deve ser frisado que não é apenas Bonavides que realiza esta leitura da Constituição de 1988, na mesma linha, em seus Cursos de direito constitucional, outros autores também demonstram isto, ao conceituar a carta cidadã como uma constituição dirigente - aquelas que visam a interferência do estado, principalmente, no plano econômico, visando atingir algum objetivo. Damos como exemplo: Gilmar Ferreira Mendes e Paulo Gonet Branco (2013, p. 63); José Afonso da Silva (2014, p. 8); Alexandre de Moraes (2014, p. 10).

44 BONAVIDES, Paulo. Curso de direito constitucional. 29. ed. São Paulo: Malheiros, 2014, p. 379.

45 CANOTILHO, José Joaquim Gomes. Direito Constitucional e Teoria da Constituição. 7. ed. Coimbra: Almedina, 2000, p. 96. 
OLIVEIRA, Heron José Castro. Estado de direito e estado democrático de direito (estado social): o que há de novo?. Revista Eletrônica Direito e Política, Programa de Pós-Graduação Stricto Sensu em Ciência Jurídica da UNIVALI, Itajaí, v.11, n.3, 30 quadrimestre de 2016. Disponível em: www.univali.br/direitoepolitica - ISSN 1980-7791.

Respondem alguns que Estado de direito e democracia correspondem a dois modos de ver a liberdade. No Estado de direito concebe-se a liberdade como liberdade negativa, ou seja, uma "liberdade de defesa" ou de "distanciação" perante o Estado. É uma liberdade liberal que "curva" o poder. Ao Estado democrático estaria inerente a liberdade positiva, isto é, a liberdade assente no exercício democrático do poder ${ }^{46}$.

Observamos que nas constituições promulgadas na segunda metade do século $X X$, e que contém a expressão "Estado Democrático de Direito ou Estado de Direito Democrático", o que é caso, respectivamente, da constituição brasileira (1988) e portuguesa (1976), os direitos sociais foram positivados de forma abundante ${ }^{47}$.

Se a liberdade no Estado Democrático de Direito é positiva, ou seja, liberdade de poder realizar. Qual sua diferença com relação ao Estado Social? Nenhuma, já que no welfare state se visavam as mesmas liberdades positivas.

\section{DIFERENÇAS ENTRE AS DUAS FORMAS DE ESTADO}

O Estado de Direito mudou seu ideário após a primeira grande guerra, quando os direitos sociais e econômicos se somaram às liberdades públicas ${ }^{48}$. Nesse cenário não se pode negar que a ideia de Estado de Direito, como função da lei baseada na ideia de limitação do poder estatal e igualdade formal, perde espaço para a ideia de Estado Social, posteriormente chamado de Estado Democrático de Direito.

${ }^{46}$ CANOTILHO, José Joaquim Gomes. Direito Constitucional e Teoria da Constituição. 7. ed. Coimbra: Almedina, 2000, p. 99.

47 Na carta política brasileira em seu artigo 60, são estipulados nada mais nada menos do que doze
direitos sociais (educação, a saúde, a alimentação, o trabalho, a moradia, o transporte, o lazer, a
segurança, a previdência social, a proteção à maternidade e à infância, a assistência aos
desamparados). Já na constituição portuguesa, logo no preâmbulo, consta: "A Assembleia
Constituinte afirma a decisão do povo português de defender a independência nacional, de garantir
os direitos fundamentais dos cidadãos, de estabelecer os princípios basilares da democracia, de
assegurar o primado do Estado de Direito democrático e de abrir caminho para uma sociedade
socialista, no respeito da vontade do povo português, tendo em vista a construção de um país mais
livre, mais justo e mais fraterno" (grifo nosso).

${ }^{48}$ FERREIRA FILHO, Manoel Gonçalves. Direitos humanos fundamentais. 14. ed. São Paulo: Saraiva, 2012, p. 59. 
OLIVEIRA, Heron José Castro. Estado de direito e estado democrático de direito (estado social): o que há de novo?. Revista Eletrônica Direito e Política, Programa de Pós-Graduação Stricto Sensu em Ciência Jurídica da UNIVALI, Itajaí, v.11, n.3, 30 quadrimestre de 2016. Disponível em: www.univali.br/direitoepolitica - ISSN 1980-7791.

De qualquer forma, a doutrina enxerga que atualmente não impera mais a ideia de Estado de Direito, aquela instituição do constitucionalismo que visava diminuir o poder estatal e garantir a igualdade de todos perante a lei, mas sim a ideia de que além de se manter omisso em relação ao particular, não o impedindo de agir, o estado também deve ter uma atitude de ação para melhor garantir o exercício de suas liberdades.

Essa ideia atual de Estado Democrático de Direito, difere muito do conceito de Estado de Direito e da ideia oitocentista de lei, muito bem exposta nesta passagem:

Não é verdade que a função da lei seja reger nossas consciências, nossas ideias, nossas vontades, nossa educação, nossos sentimentos, nosso trabalho, nosso comércio, nossos talentos ou nossos prazeres. A função da lei é proteger o livre exercício destes direitos e impedir que qualquer pessoa possa impedir qualquer cidadão de usufruir desses direitos ${ }^{49}$.

E por que houve uma mudança na visão tradicional de Estado de Direito? Por quais motivos se fez necessária a maior intervenção do Estado em outros setores? As ideias de igualdade perante a lei e liberdade negativa não são mais necessárias?

Sem dúvidas, tal acontecimento, como demonstramos, se deu pela desigualdade provocada pelo sistema capitalista, em seu início, que coincide com o fortalecimento do Estado de Direito, houve uma grande geração de riqueza jamais vista, porém, em outra ponta, a classe trabalhadora se encontrou em estado de penumbra ${ }^{50}$.

As constituições que abraçaram, de forma inédita, os direitos sociais foram as constituições de Weimar (1919), como já citada, e a constituição mexicana de 1917.

A terceira geração de direitos fundamentais, direitos de solidariedade, também ajudou a mudar a ideia clássica de Estado de Direito e somar a ideia de Justiça Social

\footnotetext{
49 BASTIAT, Frederic. A Lei. Tradução: Ronaldo da Silva Legey. 3. ed. São Paulo: Instituto Ludwig von Mises Brasil, 2010, p. 52.

50 FERREIRA FILHO, Manoel Gonçalves. Direitos humanos fundamentais. 14. ed. São Paulo: Saraiva, 2012, p. 60.
} 
OLIVEIRA, Heron José Castro. Estado de direito e estado democrático de direito (estado social): o que há de novo?. Revista Eletrônica Direito e Política, Programa de Pós-Graduação Stricto Sensu em Ciência Jurídica da UNIVALI, Itajaí, v.11, n.3, 30 quadrimestre de 2016. Disponível em: www.univali.br/direitoepolitica - ISSN 1980-7791.

a essa instituição. Tais direitos seriam a "qualidade de vida e a solidariedade entre os povos" ${ }^{15}$.

Deve-se observar que direitos como solidariedade, estão muito próximos, se é que não são sinônimos, a direitos sociais, ambos necessitam de um estado interventor e com gastos desenfreados. Ou seja, nada mudou entre a Constituição de Weimar e o início do século XXI.

\section{CONSIDERAÇÕES FINAIS}

De acordo com a literatura clássica, foi possível deduzir que o Estado de Direito surge como uma resposta ao absolutismo real, sendo uma tentativa de limitar o poder dos reis e garantir que todos sejam tratados de forma igualitária perante a lei. Também se constata que é um instituto típico do liberalismo, não sendo à toa que dois de seus teóricos são justamente Locke e Montesquieu. Devido a essa visão política o rule of law tem como duas de suas ideias centrais a isonomia e a liberdade negativa.

Atualmente, com as mudanças ocorridas, principalmente após a primeira guerra mundial, o Estado de Direito passou a ter ao lado da isonomia e das liberdades negativas, também a ideia de direitos sociais e econômicos, pois assim os indivíduos poderiam aproveitar melhor as suas liberdades.

$\mathrm{Na}$ atual constituição do Brasil, devido ao excesso de direitos sociais, vemos abraçada a concepção de Estado Democrático de Direito, um sinônimo de Estado Social, que não pode ser confundido com o ideal de Estado de Direito.

Assim, não houve mudança, diferente do defendido por maior parte da doutrina, com o surgimento do chamado Estado Democrático de Direito ou Estado de Direito Democrático, no final do século XX. O que ocorreu foi que o Estado Social alterou seu nome de forma que ficasse mais atraente.

\footnotetext{
51 FERREIRA FILHO, Manoel Gonçalves. Direitos humanos fundamentais. 14. ed. São Paulo: Saraiva, 2012, p. 75.
} 
OLIVEIRA, Heron José Castro. Estado de direito e estado democrático de direito (estado social): o que há de novo?. Revista Eletrônica Direito e Política, Programa de Pós-Graduação Stricto Sensu em Ciência Jurídica da UNIVALI, Itajaí, v.11, n.3, 30 quadrimestre de 2016. Disponível em: www.univali.br/direitoepolitica - ISSN 1980-7791.

Sustentar que o Estado Democrático de Direito é o Estado de Direito somado a democracia não é verídico, afinal a democracia já imperava nos EUA e na Inglaterra, no século XIX. O que se vê da leitura da Constituição de 1988, é que valores como liberdade negativa, isonomia e democracia, são afogados em detrimento de direitos ditos sociais, que não tem como objetivo nada mais nada menos do que garantir privilégios de classe, corporativismos, reservas de mercado e uma burocracia que premia a ineficiência estatal.

Também frisamos que em nenhum momento se procura evitar a interferência do estado, até mesmo autores liberais entende que o Estado é legítimo e necessário. Contudo, não há como negar que o Estado Democrático de Direito é o Estado Social com outro nome, sendo este fato pouco analisado nos livros de direito constitucional, tendo o tema já entrado no chamado senso comum acadêmico, visto que poucos constitucionalistas abordam ou questionam este fato.

\section{REFERÊNCIAS DAS FONTES CITADAS}

BASTIAT, Frederic. A Lei. Tradução: Ronaldo da Silva Legey. 3. ed. São Paulo: Instituto Ludwig von Mises Brasil, 2010.

BOBBIO, Norberto. Igualdade e Liberdade. Tradução: Carlos Nelson Coutinho. 5. ed. Rio de Janeiro: Ediouro, 1997.

BONAVIDES, Paulo. Curso de direito constitucional. 29. ed. São Paulo: Malheiros, 2014.

CANOTILHO, José Joaquim Gomes. Direito Constitucional e Teoria da

Constituição. 7. ed. Coimbra: Almedina, 2000.

DA SILVA, José Afonso. Curso de Direito Constitucional Positivo. 37. ed. São Paulo: Malheiros, 2014.

DIMOULIS, Dimitris; MARTINS, Leonardo. Teoria Geral dos Direitos

Fundamentais. 4. ed. São Paulo: Atlas, 2012.

DWORKIN, Ronald. Uma questão de princípio. Tradução: Luís Carlos Borges. São Paulo: Martins Fontes, 2001.

FERREIRA FILHO, Manoel Gonçalves. Curso de Direito Constitucional. 38. ed. São Pulo: Saraiva, 2012.

FERREIRA FILHO, Manoel Gonçalves. Direitos humanos fundamentais. 14. ed. São Paulo: Saraiva, 2012. 
OLIVEIRA, Heron José Castro. Estado de direito e estado democrático de direito (estado social): o que há de novo?. Revista Eletrônica Direito e Política, Programa de Pós-Graduação Stricto Sensu em Ciência Jurídica da UNIVALI, Itajaí, v.11, n.3, 30 quadrimestre de 2016. Disponível em: www.univali.br/direitoepolitica - ISSN 1980-7791.

FERREIRA FILHO, Manoel Gonçalves. Do processo legislativo. 70. Ed. São Paulo: Saraiva, 2012.

FERREIRA FILHO, Manoel Gonçalves. Estado de Direito e Constituição. 4. ed. São Paulo: Saraiva, 2007.

FERREIRA FILHO, Manoel Gonçalves. As origens do estado de direito, 1987.

Disponível em:

<http://bibliotecadigital.fgv.br/ojs/index.php/rda/article/download/45514/43918>. Acesso em: 5 jul. 2015.

HAYEK, Friedrich. Os fundamentos da liberdade. Tradução: Anna Maria Capovilla e José Ítalo Stelle. Brasília: UNB/Visão, 1983.

HOBBES, Thomas. Leviatã. Tradução: João Paulo Monteiro, Maria Beatriz Nizza da Silva, Cláudia Berliner. São Paulo: Martins Fontes, 2003.

LOCKE, John. Dois tratados sobre o governo. Tradução: Júlio Fischer. São Paulo: Martins Fontes, 2001.

MONTESQUIEU, Charles de Secondat Baron. O espírito das leis. Tradução: Cristina Marachco. 3. ed. São Paulo: Martins Fontes, 2005.

Submetido em: junho/2016

Aprovado em: setembro/2016 